\title{
Studies Abroad of Adolescents with Special Needs or \\ Disabilities
}

The case history [1] is interesting and thought-provoking. Indeed, studies abroad may be favorable for adolescents with communication abnormalities because the abnormalities are less conspicuous as the person is not typical just because he or she comes from a foreign country, due to the language barrier etc. In a foreign environment, persons with certain disabilities may be devoid of stigma and selfstigma at least temporarily [2,3]. Individuals with intellectual disabilities express interest in the opportunity to travel. Skills acquired abroad may help in future studies and work. Parents whose adult children with intellectual disabilities went on group holidays reported that upon return the children had greater confidence, decision-making and communication skills $[4,5]$. Indications should be worked out: which disabilities would benefit from studies or work abroad. A review of literature and further studies are needed. We have limited positive experience with communication abnormalities, autistic traits and/or alcohol-related problems [6]. The latter may be alleviated in non-drinking cultural settings. The clinical characteristic of Lennox-Gastaut Syndrome (epilepsy) is insufficient in [1]. Was there a genetic predisposition? The following citations from the article [1] should be commented. "Not many adolescents with or without disabilities have the opportunity to travel to find an environment that provides them opportunities to develop the necessary skills for social and occupational participation. Therefore, the results of this study cannot be generalized to all families with adolescents and young adults with disabilities"[1]. If indications would be formulated, it can be proposed to organize programs facilitating education access for students with intellectual disabilities [4] including targeted exchange for language or cultural studies abroad for adolescents with special needs. Furthermore: "In the US... there are a lot of cliques" while in the Republic of Korea the participant "Al" was a representative of her country. The "sisterly friendship", "safe and friendly environment" were noticed; "Peers in Korea made positive comments on how beautiful she was" etc. [1]. Apparently, these observations have been related to the fact that $\mathrm{Al}$ was a "young American" as per the title of the paper [1]. The attitude may change if she stays abroad longer and the environment gain more insight. Al pointed out positive experiences in Korea: "She perceived and described peers in Korea" as "more welcoming, caring and incredibly social than American peers;"

\section{Journal of}

Pediatrics \& Child Care

\author{
Jargin SV* \\ People's Friendship University of Russia, Russian Federation, \\ Russia \\ *Address for Correspondence: \\ Dr. Jargin SV, People's Friendship University of Russia, Russian \\ Federation, Clementovski per 6-82, 115184 Moscow, Russia, Tel: \\ 7495 9516788; Email: sjargin@mail.ru \\ Submission: 30 September, 2021 \\ Accepted: 20 October, 2021 \\ Published: 25 October, 2021 \\ Copyright: (๑) 2021 Jargin SV. This is an open access article distributed \\ under the Creative Commons Attribution License, which permits \\ unrestricted use, distribution, and reproduction in any medium, provided \\ the original work is properly cited.
}

"It feels really great to have a countless number of friends who really care and look out for you, unlike people in the States" [1]. Potential mechanisms and causes explaining why the girl had such impressions are not analyzed. As there is neither comparison with similar cases nor with the literature, the message may be subjective. For example, it is hard to believe that "In United States, the opportunities for kids who have learning challenges to experience college life are very limited" [1]. The grass is always greener on the other side of the fence not for everybody but for certain individuals for special reasons. Among the reasons of "xenophily" may be a disability but also affiliation with a certain minority [6]. This is important for an objective presentation.

\section{References}

1. Transition to adulthood: A qualitative case study of the lived experience of a young American adolescent in Korea. J Pediatrics Child Care 2021.

2. Makowski AC, von dem Knesebeck O (2017) Depression stigma and migration - results of a survey from Germany. BMC Psychiatry 17: 381.

3. Evans-Lacko S, Brohan E, Mojtabai R, Thornicroft G (2012) Association between public views of mental illness and self-stigma among individuals with mental illness in 14 European countries. Psychol Med 42: 1741-1752.

4. Prohn SM, Kelley KR, Westling DL (2016) Studying abroad inclusively: Reflections by college students with and without intellectual disability. J Intellect Disabil 20: 341-353.

5. McConkey R, McCullough J (2006) Holiday breaks for adults with intellectua disabilities living with older carers. Journal of Social Work 6: 65-79.

6. Jargin SV (2017) Child abuse, autism and excessive alcohol consumption. J Addiction Prevention 5: 4 